\title{
Entertainment-Education through Digital Games
}

\author{
Hua Wang \\ University of Southern California
}

Arvind Singhal

University of Texas, El Paso

Contact information:

Hua Wang

School of Communication

Annenberg School for Communication

University of Southern California

3502 Watt Way

Los Angeles, CA 90089-2081

Tel: (626) 315-7362

Email: wanghua@usc.edu

Arvind Singhal, Ph.D.

Samuel Shirley and Edna Holt Marston Endowed Professor, and

Senior Research Fellow, Sam Donaldson Center for Communication Studies

Department of Communication

University of Texas @ El Paso

El Paso, TX 79968, USA

Tel: 915-747-6286 (voicemail)

Fax: 915-747-5236

Email: asinghal@utep.edu

To appear in Ute Ritterfeld, Michael J. Cody, and Peter Vorderer (Eds.) Serious Games: Mechanisms and Effects. New York: Routledge. 


\section{Entertainment-Education through Digital Games}

Imagine yourself living in the U.S. - as an asylum seeker from Haiti; an Indian green-card holder; a Polish American citizen with legal paperwork issues and a record of misdemeanor; a Japanese foreign student; or an illegal, undocumented migrant worker from Mexico, south of the U.S. border. What happens to you if you drink and drive and are caught? Or if you engage in petty shoplifting and the shop owner calls the local police? How can these bad choices come back and haunt you? Or how about if you make better choices: For instance, not knowing a word of English, you purposefully enroll in English-language classes?

These are not hypothetical scenarios, but rather based on real cases. In early 2008, Breakthrough, an international human rights organization based in New York and New Delhi, launched ICED! I Can End Deportation, a free, 3D downloadable game that teaches players about the unjust nature of U.S. immigration laws. Primarily aimed at high school and college students, the game seeks to increase awareness about how immigration laws violate human rights by denying due process, and what

resources may exist if one finds oneself in such an unfortunate situation (Breakthrough, 2008).

Why use digital games to explore social issues such as immigration? "Games are really good at exploring complex issues, and what issue is more complex than immigration?" noted Suzanne Seggerman, President of Games for Change, an organization that supports social uses for digital games (quoted in Gorman, 2007). Immigration is only one of the important social topics being addressed via digital 
games. Health educators have used games to promote self-efficacy among children and help build self-management skills of diabetes and chronic diseases; corporations like Starbucks have collaborated with NGOs to create games to bring attention to global warming; and university students have designed games to raise empathy for migrant laborers and express their opinions about U.S.-Mexico border crossing (e.g., Brown, Lieberman, Gemeny, Fan, Wilson, \& Pasta, 1997; Lieberman, 2001; Gorman, 2007). U.N.'s aid-relief game Food Force had 4 million downloads in 15 months; more than 800,000 people played Darfur Is Dying between April and August, 2006; and there has been over 110,000 copies of Re-Mission distributed in 78 countries since its release - "techno do-gooders are proliferating, and gamers are saving the world" (Batchelder, 2006; HopeLab, 2008).

The present chapter analyzes the rise of digital games as a vehicle for entertainment-education (hereafter E-E). A (re)definition of E-E is provided accounting for the present-day digital phenomena, and a conceptual distinction is made between serious games and E-E games available in a digital format. Then building on Klimmt's explication of the common characteristics of digital games, including their potential for social change based on psycho-social models (chapter \#, in this volume), we emphasize the connection between these properties of digital games and crucial concepts and components identified from existing E-E theories and practices. Further, through illustrations, we discuss the possibilities of incorporating E-E paradigms in serious games to address complex and sensitive social issues, reach population groups beyond conventional gaming market, and stress the importance of co-production and the use of 
infrastructure in games for change. We conclude this chapter by sharing prior E-E experience of creating alternative realities through collective efficacy and action, and by problematizing the dominant psycho-social centered scholarship in conceptualizing the effects of serious games.

\section{Redefining Entertainment-Education in the Digital Era}

The idea of using entertainment media for educational or persuasive purposes is not new, but to consciously combine entertainment and education in mass and mediated communication is a relatively recent phenomenon (Singhal \& Rogers, 1999).

Seamlessly coupling the two to achieve positive socio-cultural and behavioral change is a great challenge (e.g., Nariman, 1993; Papa et al., 2000; Papa, Singhal, \& Papa, 2006; Slater, 2002a), although not insurmountable. E-E has emerged as a field of scholarship and practice focusing on "the process of purposely designing and implementing a media message to both entertain and educate, in order to increase audience knowledge about an educational issue, create favorable attitudes, and change overt behavior”

(Singhal \& Rogers, 1999, p. 9; Singhal, Cody, Rogers, \& Sabido, 2004, p. 5). Over the past three decades, several hundred E-E interventions have been designed and implemented, addressing important public health and social issues in countries of Asia, Africa, and Latin America, primarily through the use of television and radio soap operas and now increasingly in Europe and North America employing more diversified communication channels and genres (Singhal \& Rogers, 2004).

Taking into account the recent developments in the field - especially the popularity of digital entertainment media and the emerging participatory culture ${ }^{1}$, we 
propose a reformulation of the previous definition: Entertainment-education is a theory-based communication strategy for purposefully embedding educational and social issues in the creation, production, processing, and dissemination process of an entertainment program, in order to achieve desired individual, community, institutional, and societal changes among the intended media user populations.

By saying "theory based” we emphasize the crucial role of theory in each part of the E-E strategy - from design to evaluation. This phrase also refers to the multiplicity and interdisciplinary nature of human communication theories that E-E has incorporated as it has evolved. Additionally, the use of the word "embedding” is purposeful as the idea behind E-E is not just about message manipulation or about simply inserting an educational message in an entertainment program, but rather incorporating the issue, in all its nuance and subtlety, through the entire process. Thus, the social issue, the problems contained there-in, and the solutions for social change are an integral part of the E-E process. Here "process” signifies all the steps that go into an effective E-E intervention, including the development of creative ideas for programming, the actual production of media programs, as well as the dissemination, information processing, and dialogue that follows. In this definition, we also explicitly specify that the intended outcome can be "individual, community, institutional, and societal changes.” A review of effective E-E interventions indicate that although the bulk of the research has focused on assessing effects at the individual level, E-E programs often contribute to social change at the meso- and macro-level by influencing social dynamics among cultural groups, communities, organizations, and social 
systems at large. These changes take place across multiple levels and often in a non-linear manner as E-E may induce unintended consequences and encounter resistance due to selective message decoding and competitive political and economic forces. Further, we use the term "intended media user populations" to include consumers of increasingly diverse media formats such as digital games and virtual environments that E-E programs seek to engage.

In the context of the above definition of $\mathrm{E}-\mathrm{E}$, we make the distinction between what constitute serious games and what represent E-E interventions in the form of digital games. A number of organizations such as Robert Wood Johnson Foundation, Games for Change, and Games for Health have been instrumental in attracting interest in health promotion and social change among the professional gaming community. However, games that happen to address a health-related issue or happen to factor in some socio-cultural circumstances, as they are commonly defined as within the realm of serious games, are not necessarily designed, developed, and distributed with the consciousness of E-E principles. In fact, a great majority of these games are not what we can strictly call as E-E digital games. Nonetheless, many initiatives undertaken in this area hold tremendous potential and promise. Through this chapter, we hope to explore the unique contributions that serious games can make to the field of E-E, as well as the additional value that digital games can bring to traditional mass media E-E programs. 


\section{Connecting Social Affordances of Digital Games with Entertainment-Education}

The rise of Internet and interactive digital entertainment media technologies afford social possibilities that were not realized previously (Baym, 2002; also see Parks \& Roberts, 1998; Sproull \& Faraj, 1997). Social affordance ${ }^{2}$ of technologies has been defined as possibilities generated by properties of information and communication technologies that enable social interactions among individuals or groups, as well as between human and computer intelligence (Bradner, 2001; Bradner, Kellogg, \& Erickson, 1999; Hutchby, 2001; Mynatt, O’Day, Adler, \& Ito, 1998; Ruhleder, 2002; Wellman et al., 2003; Wellman \& Hogan, 2004).

In the previous chapter, Klimmt highlighted five properties of digital games that enable or afford certain social activities through game play: multimodality, interactivity, narrative, option for social (multiplayer) use, and the game frame of experience. They are explicated in a matrix of well-grounded psychological mechanisms of game play stages for change at the individual level and validated in previous research (e.g., Grodal, 2000; Lee, Park, \& Jin, 2006; Ritterfeld \& Weber, 2006; Vorderer, 2000). Here, we elaborate on each of these properties highlighting its relevance to key elements of E-E models. We think of experiential game play ${ }^{3}$ as the most unique feature of digital games, supported by increasingly sophisticated technological capacity that is closely associated with multimodality and interactivity. We also want to call attention to the important role of persuasive, interactive narrative ${ }^{4}$ and social interaction ${ }^{5}$ in enhancing the structure and infrastructure of E-E in its digital forms of communication. 


\section{Experiential Game Play}

Play is one of the "basic dramatic elements" identified by expert game designers that help create player's emotional engagement (Fullerton, Swain, \& Hoffman, 2004, p. 81). This game frame of experience or play perspective is crucial to achieve any outcome, whether enjoyment and relaxation, or knowledge gains and skill building, or other attitudinal and behavioral change (Bryant \& Vorderer, 2006; Gee, 2005, 2007; Singhal \& Rogers, 1999; Singhal, Cody, Rogers, \& Sabido, 2004; Vorderer \& Bryant, 2006; Zillmann \& Vorderer, 2000). Digital games share many common outcome possibilities with other entertainment media such as arousal and diversion. But perhaps what differentiates digital games from most other entertainment vehicles is its attribute of experiential play.

Many games now allow players to embody a human being (or an animal, or another subject) and be playful in the game world. Such playfulness fosters curiosity and experimentation, allowing gamers to explore multiple identities and experiential possibilities. “A playful approach can be applied to even the most serious or difficult subjects because playfulness is a state of mind rather than an action” (Fullerton et al., 2004, p.88). For instance, in the game Squeezed, the player takes on the role of a tree-hopping, bandana-wearing frog who leaves home to seek work abroad as a fruit picker, experiencing the trials and tribulations of living in a foreign country, under highly oppressive conditions, and preoccupied with the thought of sending monies back home to the family (Gorman, 2007). In Darfur Is Dying, a player may embody the role of a refugee girl who needs to fetch water in an environment fraught with threats and 
danger. If the refugee girl is caught, you (as player) are caught. If she suffers, you (as player) suffer (Gorman, 2007).

Such immersive game play experience is qualitatively different from the kind of vicarious experience an audience member may derive from traditional mass media entertainment genres. Through serendipitous discoveries and random encounters, players - often at the center of the actions - are more likely to understand or accept different point of views and learn lessons from unexpected consequential scenarios. Such a world that combines realistic representation and imaginative fantasies provide enormous opportunities for creativity, participation, and collaboration where alternative perspectives, collective actions, and new social norms may emerge. Games for social change need to strike a balance between individualized dynamic play experience and the game structure to optimize the ultimate outcome.

\section{Multimodality}

Multimodality is an attribute of most new information and communication technologies. Digital games, as entertainment products, often assemble cutting-edge technologies that are developed to increase the enjoyment of play experiences. Compared to traditional entertainment media, multimodality is enriched in digital games in terms of content presentation and channels of communication. Sophisticated audiovisual (re)presentation, increasingly integral haptic devices, and speech recognition capacity allow the possibility of sensory and realistic simulations (Johnson et al., 2004; McLaughlin, 2006; McLaughlin et al., 2006; Ritterfeld \& Weber, 2006) and enable a sense of realness and presence (Lee, 2004; Shapiro, Peña-Herborn, \& 
Hancock, 2006; Steuer, 1992; Tamborini \& Skalski, 2006; Wirth et al., 2007). This enhanced multimodality capacity of digital games, in addition to gaming associated activities on the Internet, offers immense opportunities for establishing infrastructure and facilitating discussions about the social content during and after game play.

\section{Interactivity}

Despite the conventional static view, traditional mass media genres of entertainment can also be interactive. For instance, radio and television programs have been taking phone calls for years and now also casting votes via the Internet and mobile technologies. Interactivity in digital games, however, is "a perceived degree that people in a communication process with at least one more intelligent being can bring a reciprocal effect to other participants of the communication process by turn-taking, feedback, and choice behavior” (Lee, Park, \& Jin, 2006, p. 263). This multilateral, real-time interactivity in digital games provides a different way of exposure, information processing, and social interaction between the player and the virtual environment, artificial intelligence-based software agents, avatars controlled by human actors, and other known and unknown game players (Lee, Park, \& Jin, 2006; Sellers, 2006; Vorderer, 2000).

A player's freedom to make choices changes the pathways of individual game play experiences and subsequent outcomes (Lee, Park, \& Jin, 2006; Ritterfeld \& Weber, 2006). Instant reactions allow for quick feedback loops to provoke deeper thinking and learning with player engagement in the plot development through dialogues, constant decision-making, as well as sense-making of previous decisions 
which can be limited in television and radio programs due to air time constraints (Gee, 2005, 2007; also see chapter \#, in this volume). With player’s personal well-being at stake (as Klimmt refers to as “increased self-reference,” also see Klimmt \& Vorderer, 2007), the situated awareness/learning becomes more powerful in stimulating and sustaining changes through increased player engagement and participation.

\section{Persuasive, Interactive Narrative}

Much of the early work on mass-mediated E-E was influenced by Mexican writer-producer-director Miguel Sabido, who formulated a methodology for the production of social soap operas grounded in multiple theoretical frameworks (i.e., social learning/cognitive theory by Bandura, 1977, 1986, 1997; dramatic theory by Bentley, 1967; archetypes by Jung, 1958, 1970; triune brain theory by MacLean, 1973; and the theory of the tones by Sabido, 2004). Key elements in the Sabido methodology include: a values grid derived from the moral framework of a specific educational issue; social modeling through the protagonist, antagonist, and satellite characters (esp., similarity modeling which evokes deep emotions as audience watch their favorite characters suffer, doubt, and ultimately triumph the obstacles and "win the victory;" and also transitional modeling, as often shown in the satellite/minor characters who take actions after they see positive changes in the main character); using cliffhangers to engage the audience, epilogues to spur discussions, and infrastructure and resources to provide accurate information and further assistance to change (Cody \& Sabido, in press; Nariman, 1993; Sabido, 2002, 2004, in press). Based on his methodology, Sabido created and produced a series of social content telenovelas in Mexico in the 
1970s and early 1980s (Singhal \& Rogers, 1999). The success of these E-E programs snowballed - in the years to follow - into a global wave in using narratives (especially melodramas) to address social problems across the world (Singhal \& Rogers, 2004; see examples in Case Box \#1, and also Singhal, Cody, Rogers, \& Sabido, 2004).

-- insert Case Box \#1 here --

Such E-E dramas hold persuasive powers to induce social change. As the audience members become immersed in the story and develop parasocial relationships with their favorite characters, they tend to be distracted from seriously questioning the educational messages, and at least temporarily accept the values and attitudes advocated by the characters. The power of narrative persuasion thus lies, in part, in the inhibited counter-arguing and suspension of disbelief (Green \& Brock, 2000; Green, Garst, \& Brock, 2004; Prentice \& Gerrig, 1999; Slater, 2002b; Slater \& Rouner, 2002). The use of narratives may be "one of the only strategies available for influencing the beliefs of those who are predisposed to disagree with the position espoused in the persuasive content” (Slater, 2002a, p. 175).

A majority of the dramatic elements in game design have to do with narrative (Fullerton et al., 2004): Premise helps situate digital games in a setting or metaphor beyond the abstract concepts of game system, often with introductions of a specific time and place, the main character(s) and objective, as well as the starting action to propel the story forward. A premise that unifies the formal and dramatic elements can make a game more enjoyable and enrich game play experience. Character and story may not be found in all games, but when included in a game as they increasingly are, 
they often create "a sense of connection for the players" (p. 81). The dramatic arc (or conflict) is at the heart of any good drama and any good game system, going through the classic pattern of exposition, rising action, climax, falling action, and resolution (p. 101), which are inherently built in the Sabido methodology for producing E-E soap operas. These dramatic elements allow for possibilities of role modeling, identification, empathy, and efficacy that facilitate the achieving of E-E goals.

Lee, Park, and Jin (2006) proposed that “interactivity and narrative can coexist and should be integrated in interactive media environments” (p. 266). Interactive narrative has many built-in psychological motivation mechanisms that help empower game players by allowing them to make choices that change the structure of the story and take actions that affect the eventual outcomes (Laurel, 1993; Lee, Park, \& Jin, 2006; Murray, 1997; Plowman, 1996; Schneider, Lang, Shin, \& Bradley, 2004; Wolf, 2001). In the present time, narratives constitute, for the most part, the background subtext in most digital games (Fullerton et al. 2004), and hence the advantages offered by complex, interactive digital media narratives (over the more linear traditional narratives) are not being fully exploited. As per Schell (2004), it is a myth that interactive storytelling in digital games is fundamentally different from traditional storytelling. In fact, it is this coupling of narrative and interactivity embedded in games that offers the greatest promise for E-E in the digital era. Fortunately, game design techniques such as branching storyline and emergent storytelling are rapidly developing (Fullerton et al., 2004). 


\section{Social Interaction}

The evolution and diffusion of the Internet (and associated digital entertainment games) have important social implications (e.g., Wellman et al., 2003; Wellman \& Hogan, 2004), especially with the extreme popularity of massively multiplayer online role-playing games such as World of Warcraft. Games increasingly include multiplayer modalities; this option not only grants gaming access to more than one person, but also opens doors to opportunities for group or collective change.

So the number of players matter. The interactions between an individual player, the game system, and other players may be presented in many different patterns: single player versus game, multiple individual players versus game, player versus player, unilateral competition, multilateral competition, cooperative play, and team competition (see Fullerton et al., 2004, p. 46). Social interaction in and around digital games can often take place at a much larger scale if you compare millions of players to one or just a few. The nature of game play requires communication in a more direct, spontaneous, informal, and potentially intimate fashion, which provides possibilities of social influence through these interwoven networks of computers and human players. This kind of social interaction may enhance the enjoyment of game play experience (Sellers, 2006), encourage collective learning (e.g., Kafai, 2006; Lieberman, 2006), creating both opportunities and barriers for community building and cultural co-construction (e.g., Greenfield 1997; Steen, Greenfield, Davies, \& Tynes, 2006).

The provision of a service delivery infrastructure, such as the availability of family planning clinics and adult literacy classrooms, has proved to be essential to the 
success of E-E initiatives centering around traditional media genres (Singhal \& Rogers, 1999; Singhal, Cody, Rogers, \& Sabido, 2004). Some scholars have studied the role of the Internet in information searching behaviors, and suggested that the two-step flow (Katz, 1957; Lazarsfeld, Berelson, \& Gaudet, 1944) has become a multi-step, multi-loop flow as people switch between online resources and human capital (Kayahara \& Wellman, 2007). E-E digital games certainly need to consider taking advantage of the infrastructure on- and off-line to provide accurate and reliable information as well as a safe space for dialogues ${ }^{6}$.

In short, the social affordances of digital games in relation to E-E are: (1) experiential game play, (2) multimodality, (3) interactivity, (4) persuasive, interactive narrative, and (5) social interaction. These five properties are interrelated and work together to provide an enjoyable and fruitful play experience (also see Wang et al., chapter \#, in this volume) and make digital games a promising platform for E-E interventions.

\section{Opening Possibilities for Entertainment-Education through Digital Games}

We believe that serious games open up possibilities to strategically incorporate E-E principles in game design to (1) address complex and sensitive social issues such as political conflicts, public policy, and sex education; (2) serve population groups that are beyond common gaming market reach, such as children and young people with medical conditions and senior citizens; and (3) provide a space for active participation in content generation and taking actions in the real world. In this section, we describe some promising examples in each of the three areas mentioned above. 
These examples are not necessarily what we have defined as E-E digital games in this chapter, but their stories shed light on a bright future where important social issues can be purposefully embedded in the game design, creation, and play experience to achieve desired attitudinal and/or behavioral change among the intended user populations.

\section{Serious Games: Seriously Complex and Sensitive Content}

Digital games “not only deliver messages, but also simulate experiences” and can be used as “rhetorical tools” (Persuasive Games, 2008). Bogost (2007) argues that digital games can reinforce existing social structures and positions, but also disrupt the existing social structures and persuade people to change their positions, leading to potentially significant and long-term social change. Under Bogost’s leadership, Persuasive Games has been an active player in creating new genres of digital games for change such as anti-advergames (e.g., Disaffected), editorial newsgames (e.g., Points of Entry), and political games (e.g., Airport Insecurity).

Another rising trend in games for change is the creation of what are termed public policy games, designed to educate the public on some aspect of a policy and help them better understand and fulfill their role as citizens in a democracy (Social Impact Games, 2008). For example, the French government launched an online game Cyber-Budget to try and find a solution to the country's financial challenges. The game allows people to balance the books. The challenge is to ensure the $€ 300$ billion budget is spent wisely. The players have the ability to cut taxes but such should be done in a way that government-run services do not fall into deficit. Every decision is thus 
whetted by fiscal and social considerations, and one can even avail an opportunity to present the budget to a virtual parliament, invite questions, feedback, and challenges (Social Impact Games, 2008). Another example is Peacemaker, winner of the Reinventing Public Diplomacy through Games Competition in 2006. The game challenges the player who takes on the role of either the Israeli Prime Minister or Palestinian President to come up with a resolution to the conflict as they react to various events in the game, from military attacks to diplomatic negotiations, as well as interactions with other political leaders and social groups (Hong, 2006).

Digital games are also seen as a potential and powerful tool for highly sensitive content, such as sex education. The unique properties of digital games make it relatively easy to customize and tailor messages towards individual needs and provide a more effective learning tool through experiential and fun game play, especially with immediate, direct, and corrective reinforcement. A group of scholars at the University of Connecticut is developing a game based on well-established learning strategies to promote safer sex among urban young adults (Farrar, Snyder, Barta, \& Lin, 2007). Digital games have also been used for sexual health promotion in other countries. A highly popular online game in the Netherlands, Super Shagland, promotes responsible sexual behavior and specifically stresses the importance of using condoms and abstinence from drinking while engaging in sex (Social Impact Games, 2008). Also, an interactive computer-based multimedia game was an effective intervention to educate marginalized Peruvian youth about sexual and reproductive health (Chib, 2008). 


\section{From Typical Gamers to “Atypical” Gamers}

Players of digital games are arguably dominated by young males, with some education and stable income, living in urban or suburban areas (Newman, 2004; Voderer \& Bryant, 2006). However, as more and more people with diverse background from all corners of the world come to play, digital games can be a powerful and effective tool to reach and better serve the population groups not considered as typical gamers.

One of the earlier issues discussed about digital games are addiction and violence. Parents and teachers are often concerned about the physical and psychological well-being of children and young adults who tend to spend excessive hours playing games, and the prevalence of violent content in games would lead to aggressive behaviors (e.g., Egli \& Meyers, 1984; Fisher, 1994; Gee, 2007; Griffiths \& Davies, 2005; Sherry, 2006; Weber, Ritterfeld, \& Kostygina, 2006). However, since late 1990s, games have been particularly designed and developed to help children and adolescents with certain medical conditions to learn about their diseases, practice self-management skills, and improve overall quality of life. Some examples of games for health include Packy \& Marlon and Bronkie: The Bronchiasaurus both designed by ClickHealth. Children who played those games regularly showed significantly higher self-efficacy and self-care ability, increased communication with parents about the disease, and a dramatic decline of emergency and urgent care hospital visits by 40 to 77 percent (Brown, et al., 1997; Lieberman, 2001; also see Lieberman, chapter \#, in this volume). Re-Mission is another excellent example of a game and community built 
for young people coping with cancer. Research from large-scale, randomized, controlled trials has shown evidence that digital games can be very effective to help educate cancer-related knowledge, provide young patients a sense of empowerment, and motivate them to adhere to medication.

The gaming community is largely constituted of, but certainly not restricted to, youth and teenagers. Senior citizens, at least in the U.S., are increasingly turning to digital games to maintain mental acuity and also to use games as a way for personal recreation and networking (e.g., IJsselsteijn, Nap, de Kort, \& Poels, 2007; Rikkdick, Drogin, \& Spector, 1987; Schueren, 1986; Vanden Abeele, \& Van Rompaey, 2006). Spurred by the popularity of the Nintendo Wii game system among older players, Erickson Retirement Communities, based in Baltimore, which manages 18 campuses with 19,000 total residents, is installing the consoles at each location. Also, Norwegian Cruise Line, whose client base includes a fair percentage of senior citizens, is also in the process of installing Wii systems on all its ships (Schiesel, 2007). A recent study on game design with and for seniors suggested that digital games can be a useful tool for the elderly to connect with their children, grandchildren and friends, fulfill their continued desire of personal growth, and keep a sense of self-value and connection to the society (Vanden Abeele \& van Rompaey, 2006).

\section{Co-Production and Collective Action!}

Digital media have lowered the threshold of user participation. A study conducted by Pew Internet and American Life Project in 2005 suggested that over half of the American teens online consider themselves "media creators"” and a third 
of them share their creations with others (Lenhardt \& Madden, 2005). The 2008 Digital Future Project reported that since 2003 an increasing number of people have shared original content on the Internet - through a blog, display of photos, or maintaining a personal website (Center for the Digital Future, 2008). This emerging participatory culture not only encourages individual creative expressions, but provides a safe space for sharing, a sense of community, and strong incentives for active participation (Jenkins, 2007).

Prior experience of designing traditional E-E programs suggests that it is crucial to include intended user groups in the content generation process (Usdin et al., 2004). The same idea can be applied to digital games and is highly recommended. It is often in this process of co-production that the designers can truly listen to the people that their program aims to serve, incorporate original concepts in the stories that they are about to tell, and in a language that can be easily understood. We are glad to see some digital game projects have taking the lead in making an effort to reach their intended user groups and produce high quality products through their collaborations. For example, in creating ICED Breakthrough partnered with various community-based organizations, and also included more than a hundred high school students and their teachers in New York City. Similarly, the production team of Re-Mission also made sure that teens and young adults with cancer were involved in the entire design and development process so the game can speak to the issues of their concern that stem from their day-to-day struggles but still be entertaining at the same time. 
ICED and Re-Mission also did a fine job of establishing infrastructure.

Creating compelling and dramatic content is important, but only when service delivery resources are provided that real change can take place. On the website of ICED, topics labeled as "What are the issues?" and "Get the word out!" are side by side with instructions for downloading and playing the game. Fact sheets of current U.S. immigration laws on detention and deportation are provided. And players are encouraged to include ICED character trading cards and game logos to their personal websites, blogs, social networking web pages, and email signatures. Re-Mission has also made a deliberate effort to build a community for young cancer patients. People can participate in their forums, read blogs, and benefit from many other resources. In both cases, the change does not stop at the finish of game play, but rather starts from there.

To sum up, many of the principles and key learning gleaned from traditional E-E initiatives can be incorporated in the design, development, and distribution of digital games. Digital games can be used to address complex social phenomena and sensitive topics, to reach and better serve population groups that are normally not considered as of interest to game developers, and to encourage collaborative learning and collective actions. In the next section, we discuss the role of digital games in broaching and presenting new alternative social realities.

\section{Digital Games and Alternative Realities}

To what extent might digital games help in opening up a slate of new interventional possibilities beyond the computer screen which may not have been 
broached before? How might digital games help social change practitioners to (virtually) suspend certain rules of existing social reality so that they can come up with new and more effective interventional strategies? Might the playing of a game that deals with a real social problem empower players to identify alternative intervention strategies that are otherwise difficult to fathom or propose?

Here the experience of E-E soap operas may be a useful starting point. One of the most promising aspects of E-E narratives lies in their potential to disseminate "new" behavioral models of collective action (Singhal, Cody, Rogers, \& Sabido, 2004). E-E programs can question existing patterns of social behavior and model new ways of dealing with past social practices. For instance, in the 1999 Soul City E-E television series in South Africa, a new collective behavior was modeled to portray how neighbors might intervene in a spousal abuse situation (Singhal \& Rogers, 2002). The prevailing cultural norm in South Africa was for neighbors, even if they wished to help a victim, not to intervene in a spousal abuse situation. Wife (or partner) abuse is seen as a private matter, carried out in a private space, with curtains drawn and behind closed doors. In the Soul City series, neighbors collectively decide to break the ongoing cycle of spousal abuse. When the next wife-beating episode occurred, they gathered around the abuser's residence and collectively banged pots and pans, censuring the abuser's actions (Usdin, Singhal, Shongwe, Goldstein, \& Shabalala, 2004).

This prime-time television soap opera episode, which earned one of the highest audience ratings in South Africa in 1999, demonstrated the importance of creatively modeling collective efficacy in order to energize neighbors, who, for social and cultural 
reasons, felt previously inefficacious. By watching the neighbors collectively act against an abuser on screen, viewers learned new ways to break the cycle of spousal abuse. Several weeks after this episode was broadcast, pot banging to stop partner abuse was reported in several communities in South Africa. Clearly, in these communities, the newly modeled behavior was discussed, debated, and decisions were made. Interestingly, patrons of a local pub in Thembisa Township in South Africa also reinvented the new collective behavior they learned from Soul City. They collectively banged bottles in the bar when a man physically abused his girlfriend (Singhal \& Rogers, 2002).

What implication does Soul City's experience with the modeling of new alternative realities (for domestic violence) hold for serious games? For one, digital games offer tremendous generative potential for broaching alternative interventional possibilities. Here the focus is not just on what a digital gaming experience yields for an individual user (or a community of users), which is in itself important, but on how these individual/collective outcomes can broaden the slate of interventional possibilities for social change. Here the argument is that creatively crafted digital games can provide useful inputs in generating new plotlines for other E-E narratives (e.g. soap operas). This coupling of digital gaming outputs as formative inputs for designing large-scale E-E initiatives can be a potentially very exciting area of theorizing and practice, something that has not been addressed before. However, in so doing, we 
problematize the dominant psycho-social theoretical frameworks that have been dominant in conceptualizing the effects of serious games, and call for alternative conceptualizations.

\section{Problematics and Wicked Questions}

We end this chapter by problematizing past and current scholarship on serious games, raising two key “wicked questions” for E-E and serious games researchers/ practitioners to address in the future. Wicked questions, unlike "trick" questions, have no right answers but can expose strait-jacketed assumptions about an issue, context, or situation, opening up options and possibilities not considered before.

Wicked Question \#1: How might one capture the complexity of social change in a serious game without trivializing it? Some years ago, at an African E-E summit in Kenya, a participant asked:“Professor Singhal, you can’t be serious about studying soap operas?” When this assertion was politely questioned, the counter assertion went something like: "Can you really address serious social topics in a genre that is mindless and escapist?” The response: “Yes, mindless and escapist but acknowledge that a soap opera is a highly complex narrative involving various characters who find themselves in different situations and face multiple consequences, and it is this open-ended narrativity of possibilities that makes it one of the most popular genres of mass media programming, cutting across geographic, national, and cultural boundaries. So, why does this genre need to be trashy, mindless, and escapist? Why can't it be mindful and thought-provoking?” 
Similarily, can a serious game - in its design and implementation - capture the complexity of the social change process in an engaging manner without grossly simplifying or trivializing it? That is the challenge. A corollary question that naturally follows is: Are there limits to what social issues serious games can and should explore? Wicked Question \#2: Why are serious game scholars, driven by psychological leanings, so wedded to theorize complex social change problems in individualistic, cognitive-processing frameworks? Behavior change models, driven by psycho-social frameworks (for instance, Klimmt, chapter \#, in this volume) focus on individuals as the locus of change. The change mechanisms revolve around plugging KAP (knowledge, attitude, and practice) gaps, targeting the existing “deficiencies” at the individual level. However, such models subscribe implicitly to questionable assumptions: For example, individuals are capable of controlling their context, are on an “even playing field,” make decisions on their own free will, and through a rational cognitive processing framework. While these assumptions may hold more water in cultures that value independence (e.g. in individualistic cultures such as the United States), they are less useful in understanding human behavior in collectivistic cultures where an individual's behavior is highly regulated and influenced by their other salient relationships. Also, in cultures where there are highly entrenched social hierarchies, or in dyadic relationships characterized by power differentials, psycho-social models of individual-level changes can be highly limiting in their explanatory power.

Can designers of serious games pay careful attention to values and beliefs embedded in specific cultural contexts, and be mindful of the social, political, and 
economic differentials that may mediate individual "play” decisions? An understanding of how individual decisions are grounded in socio-cultural contexts can open new possibilities for enacting individual, group, or community-level collective actions. For instance, in a serious game which involve various scenarios for a commercial sex worker to reduce her risk of HIV infection, alternatives may range from her individual skills in negotiating condom usage with a client to all commercial sex workers taking a collective decision that "no condom, no sex.”

In summary, the present chapter analyzed the role of digital games in the growing practice of entertainment-education. We argued that serious games should not be automatically labeled as E-E digital games just because they include some social content. Connections were drawn between the social interactional possibilities afforded by the technology of digital games vis-à-vis the more traditional mass-mediated E-E programs, expounding on the five key attributes of experiential game play, multimodality, interactivity, persuasive, interactive narrative, and social interaction. We concluded by noting that digital games offer tremendous generative potential for broaching alternative interventional possibilities for social change, and that scholarship on digital games would benefit from questioning the dominant psycho-social theoretical leanings that privilege linearity, causality, reductionism, and individual-centeredness. 


\section{References}

Bandura, A. (1977). Social learning theory. Englewood Cliffs, NJ: Prentice-Hall.

Bandura, A. (1986). Social foundation of thought and action: A social cognitive theory. Englewood Cliffs, NJ: Prentice-Hall.

Bandura, A. (1997). Self-efficacy: The exercise of control. New York: Freeman.

Batchelder, H. (2006, August 6). Do-gooder games. Retrieved February 24, 2008 from http://www.time.com/time/magazine/article/0,9171,1223388,00.html

Baym, N. K. (2002). Interpersonal life online. In L. A. Lievrouw \& S. Livingstone (Eds.), Handbook of new media (pp. 62-76). Thousand Oaks, CA: Sage.

Bentley, E. (1967). The life of drama. New York: Atheneum.

Bogost, I. (2007). Persuasive games: The expressive power of videogames. Cambridge, MA: The MIT Press.

Bradner, E. (2001). Social affordances of computer-mediated communication technology: Understanding adoption. CHI 2001.

Bradner, E., Kellogg, W., \& Erickson, T. (1999). The adoption and use of 'Babble': A field study of chat in the workplace. Proceedings of the $6^{\text {th }}$ European Conference on Computer Supported Cooperative Work (ECSCW’99), Copenhagen, Denmark, 139-158. Retrieved October 23, 2007 from http://www.research.ibm.com/SocialComputing/Papers/AdoptionOfBabble.ht m

Breakthrough. (2008). Just launched! ICED video game. Retrieved February 24, 2008 from http://www.breakthrough.tv/product_detail.asp?proid=92\&id=7 
Brown, S. J., Lieberman, D. A., Gemeny, B. A., Fan, Y. C., Wilson, D. M., \& Pasta, D. J. (1997). Educational video game for juvenile diabetes: Results of a controlled trial. Medical Informatics, 22(1), 77-89.

Bryant, J., \& Vorderer, P. (Eds.) (2006). Psychology of entertainment. Mahwah, NJ: Erlbaum.

Center for the Digital Future. (2008). The 2008 digital future report-Surveying the digital future: Year seven. USC Annenberg School for Communication. Available at http://www.digitalcenter.org

Chib, A. (2008). Network influences in health initiatives: Multimedia games for youth in Peru. Paper presented at the annual meeting of International Communication Association, Montreal, Canada.

Cody, M. J. \& Sabido, M. (in press). Entertainment-education. In W. Donsbach (Ed.) The International Encyclopedia of Communication, Oxford, England: Blackwell.

Farrar, K., Snyder, L., Barta, W., \& Lin, C. A. (2007, May). Creating positive sexual media effects using a video game. Paper presented at the annual meeting of International Communication Association, San Francisco, CA.

Egli, E. A., \& Meyers, L. S. (1984). The role of video game playing in adolescent life: Is there reason to be concerned? Bulletin of the Psychonomic Society, 22(4), 309-312.

Fisher, S. (1994). Identifying video game addiction in children and adolescents. Addictive Behaviors, 19(5), 545-553. 
Fullerton, T., Swain, C., \& Hoffman, S. (2004). Game design workshop: Designing, prototyping, and playtesting games. New York: CMP Books.

Gee, J. P. (2005). Why video games are good for your soul: Pleasure and learning. Melbourne, Australia: Common Ground.

Gee, J. P. (2007). Good video games and good learning: Collected essays on video games, learning, and literacy. New York: Peter Lang.

Gibson, J. J. (1977). The theory of affordances. In R. E. Shaw \& J. Bransford (Eds.), Perceiving, acting, and knowing: Toward an ecological psychology (pp. 67-82). Hillsdale, NJ: Erlbaum.

Gibson, J. J. (1979). The ecological approach to visual perception. Boston: Houghton Mifflin.

Gorman, A. (2007, July 9).Immigration debate finds itself in play. Retrieved May 23, 2007 from http://www.breakthrough.tv/event_details.asp?eventid=181\&id=4

Green, M. C., \& Brock, T. C. (2000). The role of transportation in the persuasiveness of public narratives. Journal of Personality and Social Psychology, 79, 401-421.

Green, M. C., Garst, J., \& Brock, T. C. (2004). The power of fiction: Determinants and boundaries. In L. J. Shrum (Ed.), The psychology of entertainment media: Blurring the lines between entertainment and persuasion (pp. 161-176). Mahwah, NJ: Erlbaum.

Greenfield, P. M. (1997). Culture as process: Empirical methods for cultural psychology. In J. W. Berry, Y. Poortinga, \& J. Pandey (Eds.), Handbook of 
cross-cultural psychology: Vol. 1. Theory and method (pp. 301-346). Boston: Allyn \& Bacon.

Griffiths, M. D., \& Davies, M. N. O. (2005). Does video game addiction exist? In J. Raessens \& J. Goldstein (Eds.), Handbook of Computer Game Studies (pp. 359-369). Boston: The MIT Press.

Grodal, T. (2000). Video games and the pleasure of control. In D. Zillmann \& P. Vorderer (Eds.), Media entertainment: The psychology of its appeal (pp. 197-214). Mahwah, NJ: Erlbaum.

Hong, Q. (2006). Peacemaker wins USC Public Diplomacy Prize. Retrieved February 25, 2008 from http://seriousgamessource.com/item.php?story=9230

HopeLab. (2008). Impact. Retrieved February 24, 2008 from http://www.hopelab.org/impact/

Hutchby, I. (2001). Conversation and technology: From the telephone to the Internet. Malden, MA: Polity.

IJsselsteijn, W. A., Nap, H. H., de Kort, Y. A. W., \& Poels, K. (2007). Digital game design for elderly users. Proceedings of Future Play 2007, 17-22.

Jenkins, H. with Clinton, K., Purushotma, R., Robinson, A. J., \& Weigel, M. (2007). Confronting the challenges of participatory culture: Media education for the $21^{\text {st }}$ century. A white paper prepared for The John D. and Catherine T. MacArthur Foundation. 
Johnson, L., Choi, S., Marsella, S., Mote, N., Narayanan, S., Vilhjlmsson, H. \& Wu, S. (2004). Tactical language training system: Supporting the rapid acquisition of foreign language and cultural skills. Proceedings of InStil, Venice, July 2004.

Jung, C. G. (1958). Psychology and religion. Translated by R. F. C. Hall. New York: Pantheon Books.

Jung, C. G. (1970). Archetypes and the collective unconscious. Buenos Aires: Editorial Paidos.

Kafai, Y. B. (2006). Playing and making games for learning: Instructionist and constructionist perspectives for game studies. Games and Culture, 1(1), 36-40.

Katz, E. (1957). The two-step flow of communication: An up-to-date report on an hypothesis. Public Opinion Quarterly, 21 (1), 61-78.

Kayahara, J., \& Wellman, B. (2007). Searching for culture- high and low. Journal of Computer-Mediated Communication, 12(3), article 4. http://jcmc.indiana.edu/vol12/issue3/kayahara.html

Klimmt, C. \& Vorderer, P. (2007). Interactive media. In J. J. Arnett (Ed.), Encyclopedia of children, adolescents, and the media (pp. 417-419). London: Sage.

Laurel, B. (1993). Computers as theater. Reading, MA: Addison-Wesley.

Lazarsfeld, P. F., Berelson, B., \& Gaudet, H. (1944). The people's choice: How the voter makes up his mind in a presidential campaign. New York: Columbia University Press.

Lee, K. M. (2004). Presence, explicated. Communication Theory, 14, 27-50. 
Lee, K. M., Park, N., \& Jin, S. (2006). Narrative and interactivity in computer games. In P. Vorderer \& J. Bryant (Eds.) Playing video games: Motives, responses, and consequences (pp. 259-274). Mahwah, NJ: Erlbaum.

Lenhardt, A., \& Madden, M. (2005). Teen content creators and consumers. A report by Pew Internet and American Life Project. Available at http://www.pewinternet.org/PPF/r/166/report_display.asp

Lieberman, D. A. (2001). Management of chronic pediatric diseases with interactive health games: Theory and research findings. Journal of Ambulatory Care Management, 24(1), 26-38.

Lieberman, D. A. (2006). What can we learn from playing interactive games? In P. Vorderer \& J. Bryant (Eds.) Playing video games: Motives, responses, and consequences (pp. 379-397). Mahwah, NJ: Erlbaum.

MacLean, P. D. (1973). A triune concept of the brain and behavior, including psychology of memory, sleep, and dreaming. In V. A. Kral et al. (Eds.), Proceedings of the Ontario Mental Health Foundation Meeting at Queen's University. Toronto: University of Toronto Press.

McLaughlin, M. L. (2006). Simulating the sense of touch in virtual environments: Applications in the health sciences. In P. Messaris \& L. Humphreys (Eds.), Digital media: Transformations in human communication (pp. 265-274). New York: Peter Lang.

McLaughlin, M. L., Zimmermann, R., Liu, L., Jung, Y., Peng, W., Jin, S., Stewart, J. Yeh, S., Zhu, W., \& Seo, B. (2006). Integrated voice and haptic support for 
tele-rehabilitation. Proceedings of UbiCare2006: First Workshop on Ubiquitous and Pervasive Healthcare.

Murray, J. H. (1997). Hamlet on the Holodeck: The future of narrative in cyberspace. New York: Free Press.

Mynatt, E. D., O’Day, V. L., Adler, A., \& Ito, M. (1998). Network communities: Something old, something new, something borrowed... Computer Supported Cooperative Work: The Journal of Collaborative Computing, 7, 123-156.

Nariman, H.N. (1993). Soap operas for social change: Toward a methodology for entertainment-education television. Westport, CT: Praeger Press.

Newman, J. (2004). Videogames. New York: Routledge.

Norman, D. (1988). The psychology of everyday things. New York: Basic Books.

Norman, D. (1990). The design of everyday things. New York: Doubleday.

Papa, M. J., Singhal, A., \& Papa, W. H. (2006). Organizing for social change: A dialectic journey of theory and praxis. New Delhi: Sage.

Papa, M. Singhal, A., Law, S., Pant, S., Sood, S., Rogers, E. M., \& Shefner-Rogers, C. L. (2000). Entertainment-education and social change: An analysis of parasocial interaction, social learning, collective efficacy, and paradoxical communication. Journal of Communication, 50, 31-55.

Parks, R. R., \& Roberts, L. D. (1998). 'Making MOOsic’: The development of personal relationships on line and a comparison to their off-line counterparts. Journal of Social and Personal Relationships, 15, 517-537. 
Persuasive Games. (2008). We design, build, and distribute electronic games for persuasion, instruction, and activism. Retrieved February 24, 2008 from http://persuasivegames.com/

Plowman, L. (1996). Narrative, linearity and interactivity: Making sense of interactive multimedia. British Journal of Educational Technology, 27, 92-105.

Prentice, D. A., \& Gerrig, R. J. (1999). Exploring the boundary between fiction and reality. In S. Chaiken \& Y. Trope (Eds.), Dual-process theories in social psychology (pp. 529-546). New York: Guilford.

Riddick, C. C., Drogin, E. B., \& Spector, S. G. (1987). The impact of videogame play on the emotional states of senor center participants. Practice Concepts, 27(4), 425-427.

Ritterfeld, U., \& Weber, R. (2006). Video games for entertainment and education. In P. Vorderer \& J. Bryant (Eds.), Playing video games: Motives, responses, and consequences (pp. 399-413). Mahwah, NJ: Erlbaum.

Ruhleder, K. (2002). Understanding on-ling community: The affordances of virtual space. Information Research, 7(3). Retrieved October 23, 2007 from http://InformationR.net/ir/7-3/paper132.html

Sabido, M. (2002). The tone, theoretical occurrences, and potential adventures, and entertainment with social benefit [in Spanish]. Mexico City: National Autonomous University of Mexico Press. 
Sabido, M. (2004). The origins of entertainment-education. In Singhal, A., Cody, M. J., Rogers, E. M., \& Sabido, M. (Eds.). Entertainment-education and social change: History, research, and practice (pp. 61-74). Mahwah, NJ: Erlbaum.

Sabido, M. (in press). The structure of the telenovela [in Spanish]. Mexico City: National Autonomous University of Mexico Press.

Schell, J. (2004). The two great myths of interactive storytelling. In T. Fullerton, C. Swain, \& S. Hoffman, Game design workshop: Designing, prototyping, and playtesting games (pp. 98-99). New York: CMP Books.

Schiesel, S. (2007, March 30). Video Games Conquer Retirees New York Times. Retrieved May 23, 2007 from http://www.gamesforchange.org/main/entry/ a_rise_in_games_for_social_change/

Schneider, E. F., Lang, A., Shin, M., \& Bradley, S. D. (2004). Death with a story: How story impacts emotional, motivational, and physiological responses to first-person shooter video game. Human Communication Research, 30(3), 361-375.

Schueren, B. (1986). Video games: An exploration of their potential as recreational activity programs in nursing homes. Activities, Adaptation, and Aging, 8(1), 49-58.

Sellers, M. (2006). Designing the experience of interactive play. In P. Vorderer \& J. Bryant (Eds.), Playing video games: Motives, responses, and consequences (pp. 9-24). Mahwah, NJ: Erlbaum. 
Shapiro, M. A., Peña-Herborn, J., \& Hancock, J. T. (2006). Realism, imagination, and narrative video games. In P. Vorderer \& J. Bryant (Eds.), Playing video games: Motives, responses, and consequences (pp. 275-290). Mahwah, NJ: Erlbaum.

Sherry, J. L. (2006). Would the great and might Oz play Doom?: A look behind the curtain of violent video game research. In P. Messaris \& L. Humphreys (Eds.), Digital media: Transformations in human communication (pp. 225-236). New York: Peter Lang.

Singhal, A., Cody, M. J., Rogers, E. M., \& Sabido, M. (Eds.). (2004). Entertainment-education and social change: History, research, and practice. Mahwah, NJ: Erlbaum.

Singhal, A., \& Rogers, E. M. (1999). Entertainment-education: A communication strategy for social change. Mahwah, NJ: Erlbaum.

Singhal, A., \& Rogers, E. M. (2004). The status of entertainment-education worldwide. In Singhal, A., Cody, M. J., Rogers, E. M., \& Sabido, M. (Eds.). Entertainment-education and social change: History, research, and practice (pp. 3-20). Mahwah, NJ: Erlbaum.

Singhal, A., Sharma, D., Papa, M. J. \& Witte, K. (2004). Air Cover and Ground Mobilization: Integrating Entertainment- Education Broadcasts with community listening and service delivery in India. In A. Singhal, M. J. Cody, E. M. Rogers \& M. Sabido, M. (Eds.), Entertainment-education and social change: History, research, and practice (351-375). Mahwah, NJ: Erlbaum. 
Slater, M. D. (2002a). Entertainment education and the persuasive impact of narrative. In M. C. Green, J. J. Strange, \& T. C. Brock (Eds.), Narrative impact: Social and cognitive foundations (pp. 157-181). Mahwah, NJ: Erlbaum.

Slater, M. D. (2002b). Involvement as goal-directed, strategic processing: The extended ELM. In J. P. Dillard \& M. Pfau (Eds.), The persuasion handbook: Developments in theory and practice (pp. 175-194). Thousand Oaks, CA: Sage.

Slater, M. D., \& Rouner, D. (2002). Entertainment-education and elaboration likelihood: Understanding the processing of narrative persuasion. Communication Theory, 12, 173-191.

Social Impact Games. (2008). Entertaining games with non-entertaining goals. Retrieved February 24, 2008 from http://www.socialimpactgames.com

Sproull, L., \& Faraj, S. (1997). Atheism, sex, and databases: The net as a social technology. In S. Kiesler (Ed.), Culture of the Internet (pp. 35-52). Mahwah, NJ: Erlbaum.

Steen, F. F., Greenfield, P. M., Davies, M. S., \& Tynes, B. (2006). What went wrong with The Sims Online: Cultural learning and barriers to identification in a massively multiplayer online role-playing game. In P. Vorderer \& J. Bryant (Eds.), Playing video games: Motives, responses, and consequences (pp. 307-323). Mahwah, NJ: Erlbaum.

Steuer, J. (1992). Defining virtual reality: Dimensions determining Telepresence. Journal of Communication, 42(4), 73-93. 
Tamborini, R. \& Skalski, P. (2006). The role of presence in the experience of electronic games. In P. Vorderer \& J. Bryant (Eds.), Playing video games: Motives, responses, and consequences (pp. 225-240). Mahwah, NJ: Erlbaum.

Usdin, S., Singhal, A., Shongwe, T., Goldstein, S., \& Shabalala, A. (2004). No short cuts in entertainment-education. Designing Soul City step-by-step. In A. Singhal, M. Cody, E. M. Rogers, \& M. Sabido (Eds.), Entertainment-education and social change: History, research, and practice (pp. 153-176). Mahwah, NJ: Erlbaum.

Vanden Abeele, V., \& Van Rompaey, V. (2006). Introducing human-centered research to game design: Designing game concepts for and with senior citizens. CHI'06, 1469-1474.

Vorderer, P. (2000). Interactive entertainment and beyond. In D. Zillmann \& P. Vorderer (Eds.), Media entertainment: The psychology of its appeal (pp. 21-36). Mahwah, NJ: Erlbaum.

Vorderer, P., \& Bryant, J. (Eds.). (2006). Playing video games: Motives, responses, and consequences. Mahwah, NJ: Erlbaum.

Weber, R., Ritterfeld, U., \& Kostygina, A. (2006). Aggression and violence as effects of playing violent video games? In P. Vorderer \& J. Bryant (Eds.), Playing video games: Motives, responses, and consequences (pp. 347-362). Mahwah, NJ: Erlbaum.

Wellman, B., Quan-Haase, A., Boase, J., Chen, W., Hampton, K., de Diaz, I. I. et al. (2003). The social affordances of the Internet for networked individualism. 
Journal of Computer-Mediated Communication, 8(3),

http://jcmc.indiana.edu/vol8/issue3/wellman.html

Wellman, B., \& Hogan, B. (2004). The immanent Internet. In J. McKay (Ed.), Netting citizens: Exploring citizenship in a digital age (pp. 54-80). Edinburgh: St. Andrew Press.

Wirth, W., Hartmann, T., Böcking, S., Vorderer, P., Klimmt, C., Schramm, H., Saari, T., Laarni, J., Ravaja, N., Ribeiro Gouveia, F., Biocca, F., Sacau, A., Jäncke, L., Baumgartner, T. \& Jäncke, P. (2007). A process model of the formation of Spatial Presence experiences. Media Psychology, 9 (3), 493-525.

Wolf, M. J. (2001). The medium of the video game. Austin, TX: University of Texas Press.

Zillmann, D., \& Vorderer, P. (Eds.). (2000). Media entertainment: The psychology of its appeal. Mahwah, NJ: Erlbaum. 
Case Box \#1. Examples of Successful E-E Programs.

From November 1975 to December 1976, 30 minutes a day, 5 times a
week, millions of Mexicans tuned in to watch a phenomenally popular
telenovela Ven Conmigo (Come with Me), depicting the journeys of a
dozen adults who overcame obstacles to enroll in literacy classes and
obtain a primary school diploma. With positive role models set by main
characters, epilogues delivered by a celebrity, and display of free
material distribution locations all carefully incorporated in the episodic
serial, adult literacy class enrollment in Mexico increased 9 fold during
the broadcast and doubled the following year (Singhal \& Rogers, 1999).
Taru, a radio soap opera broadcast weekly for a year from 2002 to
2003, in four states of India, told the story of a young woman with
feminist sensibilities who worked at the village health center. The
program addressed entrenched social problems in a highly engaging
storyline, showing the young woman protagonist in conflict with
community members. Coupling mass media with community
mobilization and service delivery, the program achieved a listenership
of an estimated 20 to 25 million people, spurring multiple listening
clubs and enthusiastic discussions on gender equality, small family size,
reproductive health, caste and communal harmony, and community
development (Singhal, Sharma, Papa, \& Witte, 2004).




\section{Endnotes}

${ }^{1}$ Here, we borrow the term and definition of "participatory culture" from the white paper entitled Confronting the challenges of participatory culture: Media education for the $21^{\text {st }}$ century by Jenkins (2007): “A participatory culture is a culture with relatively low barriers to artistic expression and civic engagement, strong support for creating and sharing one's creations, and some type of informal mentorship whereby what is known by the most experienced is passed along to novices. A participatory culture is also one in which members believe their contributions matter, and feel some degree of social connection with one another" (p. 3).

${ }^{2}$ While it originated in environmental psychology (Gibson, 1977, 1979), the term affordance was largely appropriated by Norman $(1988,1990)$ as a conceptual tool for discussing the design of interactive systems.

${ }^{3}$ We have purposefully chosen to use the term "experiential game play” instead of Klimmt's “game frame of experience" to emphasize both the "play" perspective and the "experiential” way of play related to E-E.

${ }^{4}$ We intentionally add "persuasive" and "interactive" to the label of "narrative" in this case to emphasize these characteristics of narrative in relation to its implications of E-E.

${ }^{5}$ Likewise, here we prefer the term "social interaction” over "option for social/multiplayer use” to promote the use of this element in serious game design.

${ }^{6}$ Here it is important to be mindful about the different types of play in terms of level of engagement namely spectator play, participant play, and transformational play (Fullerton et al., 2004) as the social interaction behaviors and outcomes may vary given different personalities and expectations.

${ }^{7}$ A media creator is defined as "someone who created a blog or webpage, posted original artwork, photography, stories or videos online or remixed online content into their own new creations” (Jenkins, 2007, p. 6). 